\title{
Long-term follow-up of patients undergoing endoscopic papillectomy for papillary neuroendocrine tumor: a case series and literature review
}

\author{
Facundo GALETTI ${ }^{1}$, Jessé Clementino de ARAÚJO-FILHO' ${ }^{1}$, Eliza Ribeiro Alves de ANDRADE ${ }^{1}$, \\ Eloy TAGLIERI ${ }^{1}$, Otávio MICELLI-NETO ${ }^{1}$ and José Celso ARDENGH ${ }^{1,2,3}$
}

Received: 26 October 2020

ABSTRACT - Background - Duodenal papilla neuroendocrine tumors (DP-NET) are rare. Surgical therapy may be recommended for their treatment. However, they have high rates of morbidity and mortality. Endoscopic papillectomy (EP) is safe and effective for complete resection of tumors at this site. Objective - This study aimed to describe a case series of DP-NETs resected by EP and perform a literature review. Methods - A series of patients with DP-NETs underwent EP as primary treatment between Jan/2008 and Mar/2020 at a tertiary referral center. A comprehensive search was made on the MEDLINE primary electronic database. The search strategy was designed to find all articles related to DP-NETs published in the literature. Results - Six patients underwent EP for presenting DP-NETs, four of whom were women (mean age, 63 years). The mean diameter of DP-NETs was $1.6 \pm 0.3 \mathrm{~cm}$. Four of six patients were followed up, one of whom suffered relapse at the resection site after 3 months and was referred to surgery (pT3n1b) and the remaining three patients experienced no endoscopic or histological recurrence during follow-up periods of 10, 7, and 4 years, respectively. Eighteen articles were found in the literature search in MEDLINE. The articles included case reports of endoscopically treated DP-NETs.

Conclusion - EP is safe and effective for DP-NETs that are $\leq 20 \mathrm{~mm}$, confined to the submucosal layer, well-differentiated, and without local or remote metastasis. Adequate endoscopic follow-up and definitive surgical treatment in the presence of relapse are necessary.

Keywords - Neuroendocrine tumors; endoscopic papillectomy; endoscopic ultrasonography; duodenal papilla; ampulla of Vater; endoscopic treatment; diagnosis.

\section{INTRODUCTION}

Duodenal papilla neuroendocrine tumors (DP-NET) are rare; therefore, their natural and evolutionary history is not well established ${ }^{(1)}$. They correspond to $2 \%$ of periampullary malignant neoplasms and $<1 \%$ of gastrointestinal NETs ${ }^{(2)}$. They usually have good prognosis, although a small portion may present local invasion or distant metastasis ${ }^{(3)}$. Duodenopancreatectomy (DP) and surgical ampullectomy (SA) may be recommended; however, these procedures have high rates of morbidity and mortality ${ }^{(1)}$.

Endoscopic papillectomy (EP) is safe and effective for complete resection of tumors at this site; however, good results depend on tumor size, degree of differentiation, histological invasion, and the patient's individual characteristics ${ }^{(3-7)}$. There are few studies in the literature describing the immediate and long-term results of EP in patients with DP-NETs. Thus, we report a case series of patients with DP-NETs who underwent EP, describing its main characteristics and the long-term follow-up. In addition, this report includes a literature review of described cases of patients with DP-NETs who were subjected to EP, providing information expected to be useful in therapeutic decisions for patients with DP-NETs.

\section{METHODS}

\section{Patients}

This study was approved by the institution's Research Ethics Committee, and voluntary and informed written consent was obtained from all patients who participated in the study. All patients with DP-NETs aged $>18$ years who underwent EP as the primary treatment between January 2008 and March 2020. We included patients with DP-NETs of $\leq 2.0 \mathrm{~cm}$, restricted to the duodenal papilla, and with an endoscopic biopsy positive for DP-NETs. All patients were submitted computerized tomography (CT), positron emission computerized tomography (PET/CT) or magnetic resonance imaging (MRI) before the endoscopic procedure for staging. All patients underwent endoscopic ultrasonography (EUS) immediately before EP, and there were no signs of invasion of the bile or main pancreatic duct. Exclusion criteria were patients with ulcerated or hardened tumors; those with papilla roof involvement on duodenoscopy; those shown by EUS to be at an advanced stage (>uT1 and/or $\mathrm{N}+$ and/or biliary or pancreatic intraductal invasion); and those with locoregional or radiological distant metastasis. Excluded patients were referred to surgery.

Declared conflict of interest of all authors: none

Disclosure of funding: no funding received

${ }^{1}$ Hospital 9 de Julho, Serviço de Endoscopia, São Paulo, SP, Brasil. ${ }^{2}$ Hospital das Clínicas da Faculdade de Medicina de Ribeirão Preto - Universidade de São Paulo, Departamento de Cirurgia e Anatomia, Seção de Endoscopia Digestiva (HCFMRP-USP), São Paulo, SP, Brasil. ${ }^{3}$ Universidade Federal de São Paulo (UNIFESP), Escola Paulista de Medicina, Departamento de Diagnóstico por Imagem, Programa de Pós-Graduação, São Paulo, SP, Brasil.

Corresponding author: José Celso Ardengh. E-mail: jcelso@uol.com.br 
All EUS and EP procedures were performed by experienced endoscopists, under general anesthesia or controlled sedation with propofol, with hospitalization for 2 days after the procedure. Staging and intraductal involvement were evaluated by EUS immediately before EP. All EUS examinations were performed using Fujifilm echoendoscopes, models EG-530UT, EG-530UT2, EG530UR, or EG-530UR2 (FUJIFILM Medical Systems, Wayne, New Jersey, U.S.A.). EP was indicated in cases classified as uT1 ${ }^{(8)}$.

The EP technique was always performed using same protocol. An oval or hexagonal polypectomy snare $(1.3-3 \mathrm{~cm})$ was used for apprehension of the entire tumor/papilla complex in the caudalcranial direction, with the snare initially supported on the proximal base of the papilla, then introducing the device distal to the papilla and performing the apprehension of the entire papilla, preferably using monobloc resection ${ }^{(8)}$, and applying a pure-cut monopolar current with $35 \mathrm{~W}$ output power without coagulation (Covidien WEM SS-200E electrocautery device and Valleylab Force FX electrosurgical generator, Medtronic, Dublin, Ireland). The Fujinon ED-530XT8 duodenoscope (FUJIFILM Medical Systems, Wayne, New Jersey, U.S.A.) was used.

\section{Adverse events after EP}

We observed adverse events (AEs) during the procedure, in the recovery room, and during the 2 days of hospitalization. AEs that occurred after discharge were annotated when reported by another health professional or by the patient in the subsequent follow-up consultation. We documented the AEs and classified their severity based on consensus criteria ${ }^{(9)}$. The size, number of resection fragments, and final staging of the lesion were documented. The resected specimen was recovered for histopathological evaluation.

\section{Therapeutic success of EP}

Therapeutic failure was considered to have occurred if there was invasion of the muscularis propria; lateral and/or deep-margin involvement in the resected part; positive endoscopic and/or histological tumor relapse in a control endoscopy; or endoscopic and/ or histological recurrence of the tumor during follow-up. In cases of therapeutic failure, the therapeutic conduct to be followed was evaluated by an oncological committee.

\section{Follow-up}

The post-treatment surveillance protocol (follow-up) consisted of performing an endoscopy with systematic biopsy associated with a digestive EUS in 1-3 months after the procedure (depending on the initial success of the treatment) and follow-up every 6 months for 2 years and annually for a total period of 5 years. Mean followup time was calculated in months from the initial EP to the most recent endoscopic examination or surgical intervention.

\section{Literature review}

A comprehensive search was conducted on the MEDLINE primary electronic database using as many terms as possible related to the subject, with the intention of increasing sensitivity. The search strategy was designed to find all articles related to DP-NETs published in the literature. The search was performed using the following strategy: ampullary neuroendocrine tumor OR ampullary neuroendocrine neoplasm OR neuroendocrine tumor of the ampulla of Vater OR ampullary carcinoid OR gastroduodenal neuroendocrine tumor OR gastroduodenal neuroendocrine neoplasm. Next, for evaluation and data extraction, we selected the articles in which DP-NETs were described to be treated only by endoscopy. The selection of related articles was initially made by analyzing the titles of the papers, followed by the abstracts. Articles were included after evaluating the full text.

We evaluated the characteristics of the patients included in the studies, the basic demographic data, and relevant data regarding the preoperative characteristics of the lesion; type and particularities of the endoscopic procedures performed for DP-NETs resection; and the postoperative period. Full-text studies were included, without period, format, or language limitation. The last search date was March 2020.

\section{Statistical analysis}

Categorical variables were expressed as percentages. Continuous variables were expressed as median with range and standard deviations. All statistical analyses were performed using Stata 13 (Stata Corp, College Station, TX: Stata Corp LLC).

\section{RESULTS}

\section{Patients}

During the study period, 74 patients underwent EP and 6/74 $(8.1 \%)$ for DP-NETs, 4 (66.6\%) of whom were women with a mean age of 63 years-old (22-96). None presented an association with neurofibromatosis, a condition that indicates a predisposition to DP-NETs. The clinical characteristics of all patients are presented in TABLE 1.

TABLE 1. Patient characteristics, symptoms, laboratory and EUS findings.

\begin{tabular}{lc}
\hline Characteristics & $\mathrm{n}$ \\
\hline Sex, $\mathrm{n}(\%)$ & Female, 4 (66) \\
Age (median), years (range) & $66(22-96)$ \\
Presenting symptoms, $\mathrm{n}=6$ patients & 3 \\
$\quad$ Nonspecific abdominal pain & 2 \\
Jaundice & 1 \\
Pancreatitis & \\
Clinical laboratory, median (SD) & $1.22 \pm 0.5$ \\
Total billirubin (mg/dL) & $284.3 \pm 38$ \\
Amilase (mg/dL) & 7 \\
Endoscopic ultrasound staging, $\mathrm{n}=7$ tumors* & $5.5 \pm 2.6$ \\
$\quad$ T1 N0 & \\
Mean diameter common bile duct, & $3.8 \pm 2.2$ \\
median, mm (SD) & \\
Mean diameter main pancreatic duct, \\
median, mm (SD)
\end{tabular}

All patients were detected with DP-NETs during digestive endoscopy performed for nonspecific abdominal pain ${ }^{(3)}$, pancreatitis $^{(1)}$, and jaundice ${ }^{(2)}$. The patient with pancreatitis presented changes in the imaging tests prior to the procedure, namely a dilatation of the main bile duct, which was observed by computerized tomography (CT) and confirmed by abdominal magnetic resonance imaging (MRI). Endoscopic biopsy identified DP-NETs in 5/6 patients $(83.3 \%)$ and villous adenoma in one (16.7\%). EUS staged the tumors as uT1N0 in five patients $(83.3 \%)$ and as uT1N1 in one 
patient $(16.7 \%)$. EUS-guided fine needle aspiration (EUS-FNA) reclassified UT1N1 as UT1N0 after the fine needle puncture of two peripancreatic lymph nodes performed along with the EP.

The mean diameter of DP-NETs was $1.6 \pm 0.3 \mathrm{~cm}$. One patient underwent two EPs because a synchronic DP-NET of the minor papilla was found. First, the DP-NET of the major papilla was resected, and then the tumor of the minor papilla was excised at the same time. In both tumors, DP-NETs with the same characteristics were diagnosed. Seven EPs were performed in six patients. Monoblock resection was performed in 6/7 (86\%) patients and piecemeal resection in 1/7 (14\%). Endoscopic papillotomy, pancreatic sphincterotomy, and implantation of a plastic pancreatic prosthesis to prevent acute and biliary pancreatitis were performed in $1 / 7(14 \%), 0 / 7(0 \%)$ and $1 / 7(14 \%)$ patients, respectively.

\section{Adverse events}

AEs occurred in 4/6 (66.6\%) patients. Two exhibited immediate bleeding and were successfully treated by endoscopy, and one experienced delayed bleeding ( $>24$ hours after resection), which manifested as hematochezia, also solved by endoscopy treatment. Treatment was conservative and had clinical success in patients 3 (75\%), whereas $1(25 \%)$ underwent duodenopancreatectomy (DP) immediately after EP, with disinsertion of the duodenal papilla, even after endoscopically implanting plastic prostheses in the common bile duct and MPD, and this patient was excluded from the follow-up ${ }^{(10)}$.

\section{Therapeutic success and histopathology}

Seven DP-NETs were removed from six patients. The pathological outcome was $5(71.5 \%)$ non-functioning DP-NETs and 2 $(28.5 \%)$ somatostatinomas. Of the non-functioning DP-NETs, 4 $(75 \%)$ were classified as G1 and $1(25 \%)$ as G2. Five patients met the criteria for therapeutic success of EP, even the patient who underwent duodenopancreatectomy (DP) after disinsertion of the duodenal papilla, because the operative specimen did not reveal residual neoplasm or metastatic lymph nodes ( $\mathrm{pT} 0 \mathrm{~N} 0)$, this patient was excluded from the follow-up. In one patient, the EP did not completely remove the DP-NET and was considered an immediate failure. A DP was performed shortly after EP and revealed a pT3n $1 b$ tumor, confirming the suspicion.

\section{Follow-up}

Three months after EP, 1 (16.7\%) patient, who was referred for DP, presented with tumor recurrence at the site of resection (pT3N1b stage). The other three patients did not present any endoscopic or histological recurrence during follow-up periods of 10,7 , and 4 years, respectively. Data about EP, occurrence of AEs, and follow-up are summarized in TABLE 2.

\section{Literature review}

A total of 9784 records were retrieved from MEDLINE. After evaluation of the title and abstract, studies which did not cover the topic in question were excluded. Eventually, 18 articles were selected for full-text evaluation. The 18 articles included were case reports describing DP-NETs that were endoscopically treated. The total number of patients included was 30, with $59 \%$ of female patients

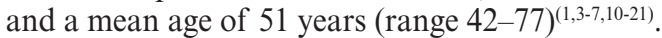

Most authors selected EP as a resection method, varying in the choice of whether to use submucosal saline injection, prophylactic stenting (pancreatic or biliary), and biliary sphincterotomy. In all
TABLE 2. Tumor characteristics, endoscopic success, adverse events, follow-up and recurrence.

\begin{tabular}{lc}
\hline Variables & $\mathrm{n}(\%)$ \\
\hline Type of resection, $\mathrm{n}=7$ tumors* & $6(86)$ \\
En bloc & $1(14)$ \\
Piecemeal & $1.8 \pm 0.4$ \\
Tumor size, mm (SD) & \\
Final pathologic finding, $\mathrm{n}=7$ tumors* & $4(58)$ \\
$\quad$ Neuroendocrine tumor & $2(28)$ \\
Somatostatinoma & $1(14)$ \\
Neuroendocrine carcinoma & $5(83.3)$ \\
Endoscopic success, $\mathrm{n}=6$ patients & $4(66.6)$ \\
Adverse events post endoscopic papillectomy, $\mathrm{n}=6$ & $2(76.8)$ \\
patients & $1(16.6)$ \\
Early bleeding & $1(16.6)$ \\
Delayed bleeding & $1(50)$ \\
Perforation (duodenal papillary disinsertion) & $1(50)$ \\
Referral to surgery after failed papillectomy, $\mathrm{n}=2 / 6$ patients \\
Early therapeutic failure \\
Perforation (duodenal papillary disinsertion) \\
Follow-Up
\end{tabular}

studies, the presence of metastasis in regional lymph nodes or at distance was excluded before subjecting the patient to the procedure, and it is noteworthy that in three patients, it was decided to perform EP after the patients rejected the surgical option.

Of the 30 patients, 23 were adequately followed-up. Two patients had positive DP-NET diagnoses during follow-up; one patient in whom DP-NET was histologically diagnosed as somatostatinoma developed liver metastases during follow-up. Another patient with DP-NET type G2, $8 \mathrm{~mm}$ in diameter, with $\mathrm{R} 1$ resection, exhibited hepatic metastases 22 months after EP. The main features of the studies are summarized in TABLES 3 and 4.

\section{DISCUSSION}

This is a retrospective study that outlines EP as a form of firstchoice treatment in patients with DP-NET of $\leq 2.0 \mathrm{~cm}$ as described in our case series. For larger non-invasive tumors of the duodenal papilla, EP is safe and effective, with an $80 \%$ long-term follow-up curative resection rate and a $33 \%$ recurrence rate. Morbidity rates vary between $9.7 \%$ and $20 \%$ and mortality rates between $0.09 \%$ and $0.3 \%{ }^{(22)}$. The present study showed that DP-NETs have a curative resection rate of $66.6 \%$ and a relapse rate of $33.3 \%$. Morbidity and mortality rates were $66.6 \%$ and $0 \%$, respectively. These data corroborate those found in the literature review.

DP and transduodenal ampullectomy are feasible surgical alternatives to EP. Both have significant rates of curative resection. However, high morbidity and mortality rates are observed. Surgical ampullectomy shows a morbidity rate of approximately $20 \%-30 \%$ and a mortality rate of $0 \%-6 \%$, whereas DP has a morbidity rate between $25 \%$ and $50 \%$ and a mortality rate between $3 \%$ and $9 \%{ }^{(23)}$. 
TABLE 3. Summary of the literature review of cases (18 reports containing data on 36 cases) of duodenal papilla neuroendocrine tumors. Patients and DP-NETs characteristics.

\begin{tabular}{|c|c|c|c|c|c|c|c|c|}
\hline \multirow{2}{*}{ Author } & \multirow{2}{*}{ Year } & \multirow{2}{*}{$\mathbf{N}$} & \multirow{2}{*}{ Age, $y /$ median } & \multirow{2}{*}{ Sex $(F-M)$} & \multirow{2}{*}{ Size $(\mathrm{mm})$} & \multirow{2}{*}{ Symptoms } & \multicolumn{2}{|c|}{ Preoperative biopsy } \\
\hline & & & & & & & DP-NET & Adenoma \\
\hline Pyun DK et al. ${ }^{(3)}$ & 2004 & 1 & 62 & $\mathrm{M}$ & 7 & NR & $(+)$ & $(-)$ \\
\hline Niido T et al. ${ }^{(19)}$ & 2005 & 1 & 51 & NR & 24 & NR & NR & NR \\
\hline Gilani $\mathrm{N}$ et al. ${ }^{(5)}$ & 2007 & 1 & 71 & M & 15 & NR & NR & NR \\
\hline Fukatsu $\mathrm{H}$ et al. ${ }^{(4)}$ & 2007 & 1 & 71 & M & 15 & NR & $(+)$ & $(-)$ \\
\hline Katsinelos P et al. ${ }^{(17)}$ & 2009 & 1 & 59 & $\mathrm{~F}$ & NR & $\mathrm{ABP}$ & NR & NR \\
\hline Odabasi $\mathrm{M}$ et al. ${ }^{(6)}$ & 2013 & 1 & 45 & $\mathrm{~F}$ & 20 & $\mathrm{ABP}$ & $(+)$ & $(-)$ \\
\hline Dhir V et al..$^{(13)}$ & 2013 & 1 & 63 & M & NR & $\mathrm{AP}$ & $(+)$ & $(-)$ \\
\hline Lee SH et al. ${ }^{(18)}$ & 2016 & 1 & 53 & $\mathrm{~F}$ & 10 & DP & $(-)$ & $(+)$ \\
\hline Attila T et al. ${ }^{(11)}$ & 2017 & 1 & NR & NR & NR & NR & NR & NR \\
\hline Fukasawa A et al. ${ }^{(15)}$ & 2017 & 1 & 57 & M & 10 & ASY & $(+)$ & $(-)$ \\
\hline Seo YK et al. ${ }^{(1)}$ & 2018 & 1 & 42 & $\mathrm{~F}$ & 16 & $\mathrm{ABP}$ & $(+)$ & $(-)$ \\
\hline Galetti F et al. & 2020 & $6 *$ & $63(\mathrm{me})$ & $(4-2)$ & 16 & $\mathrm{ABP} / \mathrm{J} / \mathrm{AP}$ & $6(+)$ & $1(+)$ \\
\hline
\end{tabular}

*One patient presented the same type of DP-NET in the major and minor duodenal papilla. (-): negative; (+): positive; DP-NET: duodenal papilla neuroendocrine tumor; NR: not reported; GERD: gastroesophageal reflux disease; DP: dyspepsia; ASY: asymptomatic; ABP: abdominal pain; J: jaundice; AP: acute pancreatitis.

TABLE 4. Summary of the literature review of cases (18 reports containing data on 36 cases). Resection type, management, adverse events, pathological results and follow-up.

\begin{tabular}{|c|c|c|c|c|c|c|c|c|c|c|}
\hline Author & $\begin{array}{l}\text { Resection } \\
\text { type }\end{array}$ & Procedure & $\begin{array}{l}\text { Adverse } \\
\text { events }\end{array}$ & Layer & Margins & $\begin{array}{l}\text { Immunohisto- } \\
\text { chemical (+) }\end{array}$ & $\begin{array}{l}\text { Ki } 67 \\
\text { Index }\end{array}$ & Mitosis & $\begin{array}{l}\text { Grading } \\
\text { criteria } \\
\text { (ENETS/ } \\
\text { WHO) }\end{array}$ & $\begin{array}{l}\text { Follow-up, } \\
\text { months }\end{array}$ \\
\hline Pyun DK et al. ${ }^{(3)}$ & EP & SSI/PPS & $\mathrm{N}$ & $\mathrm{M}$ & $(-)$ & CA / SY & NR & NR & NR & $(-), 6$ \\
\hline Chahal P et al..$^{(12)}$ & EP & Non SSI & $\mathrm{N}$ & SB & $(-)$ & CA / SY & NR & NR & NR & $(-), 14$ \\
\hline Gilani $\mathrm{N}$ et al. ${ }^{(5)}$ & $\mathrm{EP}$ & $\begin{array}{c}\text { Non SSI - PI } \\
- \text { PPS }\end{array}$ & $\mathrm{BL}(\mathrm{EH})$ & MP & NR & $\mathrm{CA} / \mathrm{SE} / \mathrm{SY}$ & NR & NR & NR & $\begin{array}{l}\text { (-) (time } \\
\text { NR) }\end{array}$ \\
\hline Katsinelos $\mathrm{P}$ et al..$^{(17)}$ & EP & Non SSI & $\mathrm{BL}(\mathrm{EH})$ & NR & NR & NR & NR & NR & NR & $(-), 4$ \\
\hline Yi H et al..$^{(7)}$ & ESD & NR & NR & SB & NR & NR & NR & NR & G2 & $(-), 6$ \\
\hline Odabasi $\mathrm{M}$ et al. ${ }^{(6)}$ & $\mathrm{EP}$ & Non SSI/PPS & $\mathrm{N}$ & MP & $(-)$ & CA / SY & $<1 \%$ & $(-)$ & G1 & $(-), 14$ \\
\hline Dhir V et al. ${ }^{(13)}$ & EP & Non SSI & $\mathrm{N}$ & NR & NR & $\mathrm{CA} / \mathrm{SY}$ & $<2 \%$ & NR & G1 & NR \\
\hline Lee SH et al. ${ }^{(18)}$ & $\begin{array}{c}\text { EP } \\
\text { (Two-step) }\end{array}$ & $\begin{array}{l}\text { SSI/PPS/ } \\
\text { (failed) }\end{array}$ & $\mathrm{N}$ & SB & $(-)$ & SY & NR & NR & G1 & $(-), 24$ \\
\hline Dogeas E et al..$^{(14)}$ & NR & NR & $\mathrm{N}$ & NR & NR & NR & NR & NR & NR & $(-), 13(\mathrm{ME})$ \\
\hline Will U et al. ${ }^{(21)}$ & NR & NR & $\mathrm{N}$ & NR & NR & NR & NR & NR & NR & NR \\
\hline Vanoli A et al. ${ }^{(20)}$ & NR & NR & $\mathrm{N}$ & NR & NR & NR & NR & NR & NR & $\begin{array}{c}1 / 4(+) \\
114(\mathrm{ME})\end{array}$ \\
\hline Gincul $\mathrm{R}$ et al. ${ }^{(16)}$ & EP & SSI / PPS & $\mathrm{N}$ & NR & $\begin{array}{l}5 / 7(-)- \\
2 / 7(+)\end{array}$ & NR & NR & NR & $\begin{array}{l}\text { 6/7 G1 / } \\
1 / 7 \mathrm{G} 2\end{array}$ & $1 / 7(+),(\mathrm{G} 2)$ \\
\hline Galetti $\mathrm{F}$ et al. & EP & Non SSI & $\begin{array}{c}3 / 4 \mathrm{BL} / 1 / 4 \\
\mathrm{PD}(\mathrm{ST})\end{array}$ & $\mathrm{M}(7)^{*}$ & $\begin{array}{c}6 / 7 *(-)- \\
1 / 7 *(+)\end{array}$ & CA / SY & $\begin{array}{l}6 / 7 *<1 \% \\
1 / 7 *>5 \%\end{array}$ & NR & $\begin{array}{c}6 / 7 * \mathrm{G} 1 / \\
1 / 7 * \mathrm{G} 2\end{array}$ & $\begin{array}{c}4 / 6(-) \\
62.2(\mathrm{ME})\end{array}$ \\
\hline
\end{tabular}

*One patient presented the same type of DP-NET in the major and minor duodenal papilla. (-): negative; (+): positive; ABP: abdominal pain; AP: acute pancreatitis; ASY: asymptomatic; BL: bleeding; CA: chromogranin A; DP: dyspepsia; DP-NET: duodenal papilla neuroendocrine tumor; EH: endoscopic hemostasis; ENETS: European Neuroendocrine Tumor Society; EP: endoscopic papillectomy; ESD: endoscopic submucosal dissection; GERD: gastroesophageal reflux disease; HPF: high-power fields; J: jaundice; M: mucosae; ME: median; MP: mild pancreatitis; MP: muscularis propria; N: non; NR: not reported; NSE: neuron-specific enolase; PD: papillary disinsertion; PI: piecemeal; PPS: plastic pancreatic stent; SB: submucosa; SE: serotonin; SO: somatostatin; SSI: submucosal saline injection; ST: surgical treatment; SY: synaptophysin; WHO: World Health Organization. G1: well differentiated dp-NET or Ki67<3\%. G2: 3-20\% Ki67. 
The current literature on the use of EP in patients with DP-NETs is scarce because the main guidelines on this subject include the therapeutic management of DP-NETs in the chapter on duodenal neuroendocrine tumors (NETs). In a recent guideline for gastrointestinal NETs, the European Neuroendocrine Tumor Society (ENETS) included DP-NETs in the management of duodenal NETs, and its therapeutic algorithm suggests the surgical treatment of all DP-NETs ${ }^{(24)}$. The National Comprehensive Cancer Network (NCCN) also includes DP-NETs in the treatment of duodenal NETs and recommends endoscopic resection in cases of non-invasive tumors, with adequate endoscopic follow$\mathrm{up}^{(25)}$. In its guidelines for subepithelial lesions, the American Society for Gastrointestinal Endoscopy (ASGE) highlights that most patients with duodenal NET have low risk of invasion of regional lymph nodes, especially tumors of $<2 \mathrm{~cm}$, which does not affect the muscularis propria ${ }^{(26)}$. ASGE guidelines recommend endoscopic resection by polypectomy or mucosectomy in well-differentiated tumors of $<1 \mathrm{~cm}$, referring the patients who exhibit invasion of the muscularis propria, histological grade $2 / 3$, or vascular and lymphatic invasion on the histological analysis of the endoscopic specimen after resection to surgery ${ }^{(26)}$. An article published by Kandler $\mathbf{J}$ et al. in the Mentoring, Education and Training Corner of the Gastroenterology journal of the American Gastroenterological Association (AGA) recommends EP for all papillary tumors of $\leq 2 \mathrm{~cm}$, while recommending definitive surgical resection in the presence of malignant or high-risk characteristics on histological analysis (R1 resection, poor differentiation, lymphovascular or submucosal invasion, the latter in the case of adenomas) $^{(22)}$.

EUS provides useful information in the evaluation of DP-NETs. It determines the degree of tumor extension (uT), accurately identifies the layer affected by the lesion (T) and identifies regional lymph nodes $(\mathrm{N})$. After the analysis of these characteristics, the patient may be referred to endoscopic or surgical treatment ${ }^{(22)}$. EUS is superior to CT, MRI, or transabdominal ultrasound for tumor staging (T) and evaluation of tumor extension into the intraductal wall ${ }^{(27)}$. Conversely, MRI was found to be superior to EUS in lymph node staging, whereas CT and positron emission tomography (PET/CT) can detect small metastases that are not detected by conventional or intraductal EUS ${ }^{(28)}$. In the present study, the TN classification by EUS underestimated $2(33.3 \%)$ patients, who were diagnosed as T1N0 at first, but in the definitive histological specimen, the tumor was classified as pT3N1b. Alternatively, the use of EUS immediately before EP provides the certainty to perform an extended EP because in the two cases reported above, the specimen from the EP presented free margins; however, during follow-up, both patients showed recurrence of the lesion. This draws attention to the fact that even when the margins are initially free, a close follow-up of these patients is fundamental.

The present study included two patients diagnosed with somatostatinoma who were asymptomatic; their diagnosis was histologically confirmed by the presence of psammoma bodies. Because these tumors are included among the functioning DPNETs, we followed the general principles of diagnosis and therapeutic management for this type of tumor. Somastotatinomas are rare, located mainly in the pancreas $(60 \%)$, and to a lesser extent in the duodenum or jejunum $(40 \%)^{(29)}$. In the duodenum and the ampullary region, somatostatinomas are usually small, with a mean size of $2.4 \mathrm{~cm}$. Histological examination shows immunoreactivity of the somatostatin type and is often associated with psammoma bodies $(11 \%)$ and to a lesser extent, with metastases at diagnosis $(30 \%-40 \%)^{(29)}$. These tumors are frequently associated with neurofibromatosis type 1 and multiple endocrine neoplasia type 1 (MEN 1). Their diagnosis and management follow the general principles adopted for NETs ${ }^{(30)}$.

Regarding for the limitations of this case series, it is a retrospective study limited by the rarity of the disease. This is real problem evidenced by the fact that this study's review of the literature found only 30 patients treated with EP. If the six cases from the present series are added, the total remains 36 . Still, EP appears to be an attractive method to treat patients with DP-NETs immediately after an EUS examination has been conducted, providing substantial information to aid in a well-founded therapeutic decision for this type of patient.

Recently, the use of endoscopic resection of DP-NETs from the ampullary region has increased as an alternative to conventional surgery. As in all neoplastic lesions, in the choice of therapeutic conduct, it is necessary to consider factors related to the patient, the lesion, and the procedure itself, such as comorbidities, age, expected life expectancy, tumor stage, and risk of locoregional or distant metastases. All these factors imply that the therapeutic management of DP-NETs should be personalized for each patient.

According to our literature review EP preceded by EUS examination for staging is safe and effective for lesions that are $\leq 20 \mathrm{~mm}$, restricted to the submucosal layer, well-differentiated, and without local or remote metastasis. Adequate endoscopic follow-up and definitive surgical treatment is necessary in the presence of relapse, positive margins, or perilesional lymph nodes.

\section{ACKNOWLEDGEMENTS}

We would like to thank Juliana Silveira Lima de Castro (https:// orcid.org/0000-0003-0280-8356) and Juan Pablo Roman-Serrano (https://orcid.org/0000-0002-0453-5323) for their scientific contribution, concepts and design, and writing-review \& editing for this study.

\section{Authors' contribution}

Galetti F, Micelli-Neto O, Araújo-Filho JC, Andrade ERA, Taglieri E: acquisition, analysis and interpretation of data. Galetti $\mathrm{F}$ : conceptualization, data curation, formal analysis, writing-review \& editing. Galetti F, Andrade ERA, Araújo-Filho JC: writingoriginal draft. Taglieri E, Ardengh JC: supervision, visualization and final approval of the version to be published.

\section{Orcid}

Facundo Galetti: 0000-0001-9569-1702.

Jessé Clementino de Araújo-Filho: 0000-0003-2443-4324.

Eliza Ribeiro Alves de Andrade: 0000-0003-4364-7878.

Eloy Taglieri: 0000-0003-1039-793X.

Otávio Micelli-Neto: 0000-0003-3803-5578.

José Celso Ardengh: 0000-0002-5932-2499. 
Galetti F, Araújo-Filho JC, Andrade ERA, Taglieri E, Micelli-Neto O, Ardengh JC. Seguimento de longo prazo de pacientes com tumor neuroendócrino da papila duodenal submetidos à papilectomia endoscópica: série de casos e revisão da literatura. Arq Gastroenterol. 2021;58(2):240-5.

RESUMO - Contexto - Tumores neuroendócrinos da papila duodenal (TNE-PD) são raros. A cirurgia deve ser recomendada para o tratamento. No entanto, apresentam altas taxas de morbimortalidade. A papilectomia endoscópica (PE) é segura e eficaz para a ressecção completa de tumores nesta região. Objetivo - Descrever uma série de casos de TNEs-PD ressecados por PE e realizar uma revisão da literatura. Métodos - Pacientes com TNEs-PD submetidos a PE como tratamento primário com intenção curativa entre jan/2008 e mar/2020 em um centro de referência terciário foram estudados. Uma pesquisa abrangente foi feita no MEDLINE. A estratégia de busca foi desenhada para encontrar todos os artigos relacionados a TNEs-PD publicados na literatura, que haviam sido submetidos a PE. Resultados - Seis pacientes foram submetidos a PE por apresentar TNEs-PD, sendo quatro mulheres, com média de idade de 66 anos (22-96). O diâmetro médio dos TNEs-PD foi de 1,8 $\pm 0,4 \mathrm{~cm}$. Quatro dos seis pacientes foram acompanhados, um dos quais sofreu recidiva no local da ressecção após 3 meses e foi encaminhado para cirurgia (pT3n1b), e os três pacientes restantes não apresentaram recorrência endoscópica ou histológica durante os períodos de acompanhamento de 10, 7 e 4 anos, respectivamente. Dezoito artigos foram encontrados no MEDLINE. Os artigos incluíram relatos de casos de TNEs-PD tratados pela PE. Conclusão - A PE é segura e eficaz para TNEs-PD $\leq 20 \mathrm{~mm}$, confinados à camada submucosa, bem diferenciados e sem metástases locais ou remotas. Acompanhamento endoscópico adequado e tratamento cirúrgico definitivo na vigência de recidiva são necessários.

Palavras-chave - Tumor neuroendócrino; papilectomia endoscópica; ultrassonografia endoscópica; papila duodenal; ampola de Vater; tratamento endoscópico; diagnóstico.

\section{REFERENCES}

1. Seo YK, Choi JS. Endoscopic Papillectomy for Synchronous Major and Minor Duodenal Papilla Neuroendocrine Tumors. Korean J Gastroenterol. 2018;72:21721.

2. Waisberg J, Joppert-Netto G, Vasconcellos C, Sartini GH, Miranda LS, Franco MI. Carcinoid tumor of the duodenum: a rare tumor at an unusual site. Case series from a single institution. Arq Gastroenterol. 2013;50:3-9.

3. Pyun DK, Moon G, Han J, Kim MH, Lee SS, Seo DW, et al. A carcinoid tumor of the ampulla of Vater treated by endoscopic snare papillectomy. Korean J Intern Med. 2004;19:257-60.

4. Fukatsu H, Kawamoto H, Fujii M, Tsutsumi K, Kato H, Hirao K, et al. Periampullary carcinoid tumor. Endoscopy. 2007;39 Suppl 1:E49-50.

5. Gilani N, Ramirez FC. Endoscopic resection of an ampullary carcinoid presenting with upper gastrointestinal bleeding: a case report and review of the literature. World J Gastroenterol. 2007;13:1268-70.

6. Odabasi M, Yildiz KM, Cengiz E, Hasan AH, Gunay E, Ozkan E, et al. Treatment of ampullary neuroendocrine tumor by endoscopic snare papillectomy. Am J Case Rep. 2013;14:439-43.

7. Yi H, Wu C, Mou Y, Liu W, Li J, Zhang Q, et al. Successful en bloc resection of papillary neuroendocrine tumors by duodenoscope using endoscopic submucosal dissection method. Clin Res Hepatol Gastroenterol. 2012;36:e100-3.

8. Taglieri E, Micelli-Neto O, Bonin EA, Goldman SM, Kemp R, Dos Santos JS, et al. Analysis of risk factors associated with acute pancreatitis after endoscopic papillectomy. Sci Rep. 2020;10:4132

9. Cotton PB, Eisen GM, Aabakken L, Baron TH, Hutter MM, Jacobson BC, et al. A lexicon for endoscopic adverse events: report of an ASGE workshop. Gastrointest Endosc. 2010;71:446-54.

10. Ardengh JC, Lemos de Bonotto M, Surjan R, Pereira Lima J, Machado MA. Unprecedented case of duodenal papillary disinsertion after endoscopic papillectomy for a neuroendocrine tumor. Endoscopy. 2015;47 Suppl 1 UCTN:E127-8.

11. Attila T, Parlak E, Alper E, Disibeyaz S, Cicek B, Odemis B. Endoscopic papillectomy of benign ampullary lesions: Outcomes from a multicenter study. Turk J Gastroenterol. 2018;29:325-34.

12. Chahal P, Prasad GA, Sanderson SO, Gostout CJ, Levy MJ, Baron TH. Endoscopic resection of nonadenomatous ampullary neoplasms. J Clin Gastroenterol. 2007;41:661-6.

13. Dhir V, Joshi N, Vivekanandarajah S, Bhandari S, Bapat M, Maydeo A. Recurrent acute pancreatitis in a patient with wirsungocele and neuroendocrine tumor of ampulla of Vater. JOP. 2013;14:99-101.

14. Dogeas E, Cameron JL, Wolfgang CL, Hirose K, Hruban RH, Makary MA, et al. Duodenal and Ampullary Carcinoid Tumors: Size Predicts Necessity for Lymphadenectomy. J Gastrointest Surg. 2017;21:1262-9.
15. Fukasawa H, Tounou S, Nabetani M, Michida T. Endoscopic Resection of Ampullary Neuroendocrine Tumor. Intern Med. 2017;56:499-503.

16. Gincul R, Ponchon T, Napoleon B, Scoazec JY, Guillaud O, Saurin JC, et al. Endoscopic treatment of sporadic small duodenal and ampullary neuroendocrine tumors. Endoscopy. 2016;48:979-86.

17. Katsinelos P, Kountouras J, Zavos C, Chatzimavroudis G, Paroutoglou G. Recurrent acute pancreatitis caused by intra-ampullary carcinoid tumor. Gastrointest Endosc. 2009;69:1387-8; discussion 8.

18. Lee SH, Lee TH, Jang SH, Choi CY, Lee WM, Min JH, et al. Ampullary neuroendocrine tumor diagnosed by endoscopic papillectomy in previously confirmed ampullary adenoma. World J Gastroenterol. 2016;22:3687-92.

19. Niido T, Itoi T, Harada Y, Haruyama K, Ebihara Y, Tsuchida A, et al. Carcinoid of major duodenal papilla. Gastrointest Endosc. 2005;61:106-7.

20. Vanoli A, La Rosa S, Klersy C, Grillo F, Albarello L, Inzani F, et al. Four Neuroendocrine Tumor Types and Neuroendocrine Carcinoma of the Duodenum: Analysis of 203 Cases. Neuroendocrinology. 2017;104:112-25.

21. Will U, Muller AK, Fueldner F, Wanzar I, Meyer F. Endoscopic papillectomy: data of a prospective observational study. World J Gastroenterol. 2013;19:4316-24.

22. Kandler J, Neuhaus H. How to Approach a Patient With Ampullary Lesion. Gastroenterology. 2018;155:1670-6.

23. Klein A, Tutticci N, Bourke MJ. Endoscopic resection of advanced and laterally spreading duodenal papillary tumors. Dig Endosc. 2016;28:121-30.

24. Delle Fave G, O'Toole D, Sundin A, Taal B, Ferolla P, Ramage JK, et al. ENETS Consensus Guidelines Update for Gastroduodenal Neuroendocrine Neoplasms. Neuroendocrinology. 2016;103:119-24.

25. Clark OH, Benson AB, 3rd, Berlin JD, Choti MA, Doherty GM, Engstrom PF, et al. NCCN Clinical Practice Guidelines in Oncology: neuroendocrine tumors. J Natl Compr Canc Netw. 2009;7:712-47.

26. Standards of Practice C, Faulx AL, Kothari S, Acosta RD, Agrawal D, Bruining $\mathrm{DH}$, et al. The role of endoscopy in subepithelial lesions of the GI tract. Gastrointest Endosc. 2017;85:1117-32.

27. Ridtitid W, Schmidt SE, Al-Haddad MA, LeBlanc J, DeWitt JM, McHenry L, et al. Performance characteristics of EUS for locoregional evaluation of ampullary lesions. Gastrointest Endosc. 2015;81:380-8.

28. Chen $\mathrm{CH}$, Yang CC, Yeh YH, Chou DA, Nien CK. Reappraisal of endosonography of ampullary tumors: correlation with transabdominal sonography, CT, and MRI. J Clin Ultrasound. 2009;37:18-25.

29. Robert T. Pancreatic Endocrine Tumors. Goldman's Cecil Medicine. Twenty Fourth ed2012. p. 1292-7.

30. Run YU. Neuroendocrine Tumor Sindromees. Endocrinology: Adults and Pediatric. II. Seventh ed2016. 